\title{
Distribution of diabetic retinopathy among diabetics in southern province of Sri Lanka
}

\author{
Wimalasundera Saman \\ Community Medicine,Department of Community Medicine, Ophthalmologist,Community Ophthalmology Center, Faculty of \\ Medicine,University of Ruhuna, Galle, Sri Lanka
}

\section{Email address:}

samanwimalasundera@gmail.com

\section{To cite this article:}

Wimalasundera Saman. Distribution of Diabetic Retinopathy among Diabetics in Southern Province of Sri Lanka. European Journal of Preventive Medicine. Special Issue: New Frontiers of Public Health from the Pearl of Indian Ocean, Sri Lanka.

Vol. 3, No. 2-1, 2015, pp.5-8. doi: 10.11648/j.ejpm.s.2015030201.12

\begin{abstract}
Diabetic Retinopathy (DR) refers to a group of pathologies found in the retina ofdiabetics that can lead to visual complications. Screening for DR is immensely useful in preventing blindness.Diabetic patients who were registered in the diabetic clinic of a leading hospital in the private sector over a period of one year were selected for this study. Total of 2603 diabetics were examined majority $(97.0 \%)$ were Sinhala. They represented three districts of Southern province. Males were $64.3 \%$. Majority belonged to the diabetic duration of $5-15$ years. (72.9\%). Total prevalence of DR was 7.53\%. (Bilateral 5.5\% and Unilateral 2.0\%). Lowest prevalence value was shown in the age category of below 30yrs and the highest value of $10.9 \%$ in $51-60 y r s$ group. The total prevalence of maculopathy was $0.6 \%$ with a higher age specific value in $51-60$ group. Prevalence of pre proliferative and proliferative DR was only $0.12 \%$. A steady increase was shown in the appearance of DR with the duration of diabetes. An obvious association with the occurrence of retinopathy and hypertension was shown than non hypertension patients.
\end{abstract}

Keywords: Diabetic Retinopathy. Maculopathy, Hypertension

\section{Introduction}

Diabetic retinopathy (DR) refers to a group of pathologies found in the retina of individuals having diabetes mellitus for a long duration as a complication. DR has serious consequences on the visual acuity of patients even leading to blindness. The presence of DR indicate complications of DR in other organs too. There are differences in the prevalence values in different studies. It may be due to different study designs however DR is a common complication in long term diabetes mellitus. The control of glycemia decreases the risk of incidence of DR and the progression of DR. [1,2 ]

The micro aneurysms in the retina is usually the first lesion to be detected by ophthalmoscopy.It appears as a red spot of about $20-200 \mu m$ in diameter and contiguous with small blood vessels. It is lined with endothelium and has increased permeability. Blot and flame shape hemorrhages appear in the nerve fiber layer at the same time. Hemorrhages may disappear and exudates begin to develop appearing as yellow deposits. Those are larger than micro aneurysms. The origins of such hard exudates are from leaky capillary blood vesselsand micro aneurysms. Soft exudates (cotton wool spots) may also appear in retina. These are infracted areas in the nerve fiber layer of retina. Soft exudates are white lesions without discrete margins. They may disappear subsequently at any time. The detection of DR, either the presence or the grade, requires a careful examination of fundi with a direct ophthalmoscope (normal or wide angles) after dilatation of pupils. Another method used is taking high quality standardized photograph of the retina. This is very costly. $[3,4]$

\subsection{Pre Proliferative Retinopathy}

At this stage changes occur due to ischemia of retina. There may be dilatation of retinal capillary bed, sometimes appears as a mass of red threads or may consists of only few dilated vessels. The vessels may develop segments resembling beading and may look like a stringe of sausages. Duplication of veins may develop appearing parallel veins in some area. Some segments of arterioles may appear constricted. 


\subsection{Proliferative Retinopathy}

In this stage growth of new blood vessels (Thin walled and fragile) occur in the retina.The symptoms appear only after bleeding occurs from new vessels. Vision is obscured due to bleeding.Fibro vascular tissues develop causing traction on the retina,that lead to retinal detachment.[5,6]

\subsection{Diabetic Maculopathy(Macula Oedema)}

1 When blood vessels around macula area start leaking, it causes macula oedema or diabetic maculopathy. It distorts the visual image and reduces visual acuity. Sometimes this might not appear clinically until such time more severe maculopathy occur. It may occur in the presence of either non proliferative or proliferative retinopathy. $[7,8]$

\subsection{Objectives of the Study}

2 To find the prevalence and distribution of diabetic retinopathy among diabetic patients attending to a diabetic center in Galle district.

3 To find the association betweenhypertension and severity of retinopathy in people with diabetes.

\section{Methodology}

4 Identification of DR requires a diabetic register to find the population at risk. [9]

The people who are registered at diabetic center of cooperative hospital of Galle were selected for this study. Diagnosed diabetic patients who attended the above center for a period of one year starting from $1^{\text {st }}$ January 2012 to $31^{\text {st }}$ December 2013 were selected for this study irrespective of the duration of the onset of diabetes mellitus. A questionnaire on basic demographic data and a protocol for diabetic screening was developed and validated to be used in the screening programme. Screening was done after dilating the pupils and using a wide angle direct ophthalmoscope. The principal investigator who is an eye surgeon did all screening to reducepersonnel bias. About $10 \%$ of detected DR cases were subjected to fundus photography to confirm the diagnosis. Adequate arrangements were made to obtain treatment for DR cases who needed treatment at a tertiary center. Records were maintained on false positives (Macula degenerations Drusen, etc. transferred back to screener from tertiary center). Another $10 \%$ sample of negative cases also re screened.

\section{Findings}

Total of 2603 diabetics were examined. Their demographic details were as follows.

Table 1. Geographical distribution

\begin{tabular}{lllll}
\hline Galle & Matara & Hambanthota & Other & Total \\
\hline 1901 & 586 & 76 & 40 & 2603 \\
$73.0 \%$ & $22.5 \%$ & $3.0 \%$ & $1.5 \%$ & \\
\hline
\end{tabular}

Table 2. Age distribution in years

\begin{tabular}{|c|c|c|c|c|c|c|}
\hline $\begin{array}{l}\text { Below } \\
30 \\
\end{array}$ & $31-40$ & $41-50$ & $51-60$ & $\begin{array}{l}\text { Above } \\
61\end{array}$ & $\begin{array}{l}\text { Not } \\
\text { marked }\end{array}$ & Total \\
\hline 76 & 434 & 805 & 884 & 401 & 03 & 2602 \\
\hline $1.6 \%$ & $10.7 \%$ & $30.9 \%$ & $33.9 \%$ & $15.4 \%$ & $0.1 \%$ & 2603 \\
\hline \multicolumn{7}{|c|}{ Table 3. Sex distribution } \\
\hline Male & & \multicolumn{2}{|c|}{ Female } & & \multicolumn{2}{|c|}{ Total } \\
\hline 1674 & & \multicolumn{2}{|c|}{929} & & \multirow{2}{*}{2603} & \\
\hline $64.3 \%$ & & \multicolumn{2}{|c|}{$35.4 \%$} & & & \\
\hline
\end{tabular}

Table 4. Ethnic distribution

\begin{tabular}{llllll}
\hline Sinhala & Tamil & Muslim & Other & Not marked & Total \\
\hline 2525 & 24 & 59 & 04 & 01 & \multirow{2}{*}{2603} \\
$97.0 \%$ & $0.9 \%$ & $2.3 \%$ & $0.2 \%$ & $0.03 \%$ & \\
\hline
\end{tabular}

Table 5. Diabetic duration in the sample

\begin{tabular}{|c|c|c|c|c|c|c|c|}
\hline $\begin{array}{l}\text { Below } \\
\text { 1yrs } \\
\end{array}$ & $\begin{array}{l}1- \\
5 y r s \\
\end{array}$ & $\begin{array}{l}6- \\
10 y r s \\
\end{array}$ & $\begin{array}{l}11- \\
15 y r s\end{array}$ & $\begin{array}{l}16- \\
20 y r s \\
\end{array}$ & $\begin{array}{l}\text { Above } \\
21 \mathrm{yrs}\end{array}$ & $\begin{array}{l}\text { Not } \\
\text { marked }\end{array}$ & Total \\
\hline 534 & 929 & 679 & 289 & 109 & 50 & 13 & \multirow{2}{*}{2603} \\
\hline $20.5 \%$ & $35.7 \%$ & $26.1 \%$ & $11.1 \%$ & $4.2 \%$ & $1.92 \%$ & $0.5 \%$ & \\
\hline
\end{tabular}

Table 6. Prevalence of retinopathy according to age categories(Maculopathy included)

\begin{tabular}{|c|c|c|c|c|c|c|c|}
\hline \multicolumn{2}{|l|}{$\overline{\text { Age }}$} & \multicolumn{2}{|c|}{$\begin{array}{l}\text { Bilateral } \\
\text { Retinopathy }\end{array}$} & \multicolumn{2}{|c|}{$\begin{array}{l}\text { Unilateral } \\
\text { Retinopathy }\end{array}$} & \multicolumn{2}{|c|}{ Total } \\
\hline Below 30 & $\mathrm{n}=76$ & & & 01 & & 01 & $1.31 \%$ \\
\hline $31-40$ & $\mathrm{n}=434$ & 06 & & 08 & & 14 & $3.22 \%$ \\
\hline $41-50$ & $\mathrm{n}=805$ & 46 & & 09 & & 55 & $8.83 \%$ \\
\hline $51-60$ & $\mathrm{n}=884$ & 73 & & 23 & & 96 & $10.85 \%$ \\
\hline Above 61 & $\mathrm{n}=401$ & 18 & & 12 & & 30 & $7.48 \%$ \\
\hline Total & $\mathrm{n}=2603$ & 143 & $5.5 \%$ & 53 & $2.03 \%$ & 196 & $7.53 \%$ \\
\hline
\end{tabular}

The total prevalence of diabetic retinopathy in the sample was $7.5 \%$ whilst bilateral retinopathy was present in $5.5 \%$ and unilateral retinopathy was identified in $2.0 \%$.

Table 7. Prevalence of maculopathy according to Age categories

\begin{tabular}{llllll}
\hline Age & & $\begin{array}{l}\text { Bilateral } \\
\text { Maculopathy }\end{array}$ & $\begin{array}{l}\text { Unilateral } \\
\text { Maculopathy }\end{array}$ & \multicolumn{2}{l}{ Total } \\
\hline Below 30 & $\mathrm{n}=76$ & & 01 & 01 & $1.31 \%$ \\
$31-40$ & $\mathrm{n}=434$ & & & 00 & \\
$41-50$ & $\mathrm{n}=805$ & 02 & 04 & 06 & $0.74 \%$ \\
$51-60$ & $\mathrm{n}=884$ & 04 & 03 & 07 & 0.79 \\
Above 61 & $\mathrm{n}=401$ & 01 & 00 & 01 & $0.24 \%$ \\
Total & $\mathrm{n}=2603$ & 07 & 08 & 15 & $0.57 \%$ \\
\hline
\end{tabular}

The occurrence of Maculopathy in the sample was low compared to retinopathy amounting to $0.6 \%$ of the total.It was more prevalent in older age groups.

Table 8. Prevalence of pre-proliferative and Proliferative retinopathy according to age categories

\begin{tabular}{|c|c|c|c|c|c|c|c|}
\hline & & $\begin{array}{l}\text { Below } \\
30\end{array}$ & $\begin{array}{l}31 \\
- \\
40\end{array}$ & $\begin{array}{l}41 \\
- \\
50\end{array}$ & $\begin{array}{l}51 \\
- \\
60\end{array}$ & $\begin{array}{l}\text { Above } \\
61\end{array}$ & Total \\
\hline \multirow{5}{*}{$\begin{array}{l}\text { Pre } \\
\text { proliferative } \\
\text { retinopathy } \\
\text { Proliferative } \\
\text { retinopathy } \\
\text { Total }\end{array}$} & Bilateral & 00 & 00 & 00 & 00 & 00 & 00 \\
\hline & Unilateral & 00 & 00 & 00 & 01 & 01 & 02 \\
\hline & Bilateral & 00 & 00 & 01 & 00 & 00 & 01 \\
\hline & Unilateral & 00 & 00 & 00 & 00 & 00 & 00 \\
\hline & & 00 & 00 & 01 & 01 & 01 & 03 \\
\hline
\end{tabular}


The prevalence of pre-proliferative or proliferative retinopathy in the sample was $0.12 \%$. It was mainly seen in older age groups.

Table 9. Prevelence of retinopathy according to diabetic duration

\begin{tabular}{|c|c|c|c|c|c|c|}
\hline \multirow[b]{2}{*}{ Retinopathy } & \multicolumn{6}{|c|}{ Diabetic duration in year } \\
\hline & $\begin{array}{l}\text { Below 1yrs } \\
n=534\end{array}$ & $\begin{array}{l}1-5 \\
n=929\end{array}$ & $\begin{array}{l}6-10 \\
n=679\end{array}$ & $\begin{array}{l}11-15 \\
n=289\end{array}$ & $\begin{array}{l}16-20 \\
n=109\end{array}$ & $\begin{array}{l}\text { Above21 } \\
n=50\end{array}$ \\
\hline \multirow{2}{*}{ Bilateral } & 04 & 22 & 50 & 37 & 19 & 11 \\
\hline & $0.74 \%$ & $2.36 \%$ & $7.36 \%$ & $12.80 \%$ & $17.43 \%$ & $22.0 \%$ \\
\hline \multirow{2}{*}{ Unilateral } & 03 & 13 & 19 & 09 & 05 & 04 \\
\hline & $0.56 \%$ & $1.39 \%$ & $2.79 \%$ & $3.11 \%$ & $4.58 \%$ & $8.0 \%$ \\
\hline Total & 07 & 35 & 69 & 46 & 24 & 15 \\
\hline
\end{tabular}

A steady increase of the presence of D.R was seen with the duration of D.M

Table 10. Association of Retinopathy and Hypertension in diabetic subjects

\begin{tabular}{|c|c|c|c|c|c|c|c|}
\hline \multirow{2}{*}{$\begin{array}{l}\text { Diabetic duration } \\
\text { Below 1yrs. }\end{array}$} & \multirow{2}{*}{$\begin{array}{l}\text { Hypertention } \\
82\end{array}$} & \multicolumn{2}{|c|}{ Retinopathy + Hypertention } & \multicolumn{3}{|c|}{ Retinopathy without Hypertention } & \multirow{2}{*}{$\begin{array}{l}\text { Total } \\
07\end{array}$} \\
\hline & & 04 & $4.8 \%$ & $N=452$ & 03 & $0.6 \%$ & \\
\hline $1-5$ & 192 & 09 & $4.7 \%$ & $N=737$ & 26 & $3.9 \%$ & 35 \\
\hline $6-10$ & 201 & 23 & $11.4 \%$ & $\mathrm{~N}=478$ & 46 & $9.0 \%$ & 69 \\
\hline $16-20$ & 43 & 12 & $27.9 \%$ & $\mathrm{~N}=66$ & 12 & $18.1 \%$ & 24 \\
\hline Above 21 & 28 & 11 & $39.2 \%$ & $\mathrm{~N}=22$ & 04 & $18.1 \%$ & 15 \\
\hline Total & 642 & 75 & $11.7 \%$ & 1948 & 121 & $6.2 \%$ & 196 \\
\hline
\end{tabular}

Duration was not given by 13 subjects

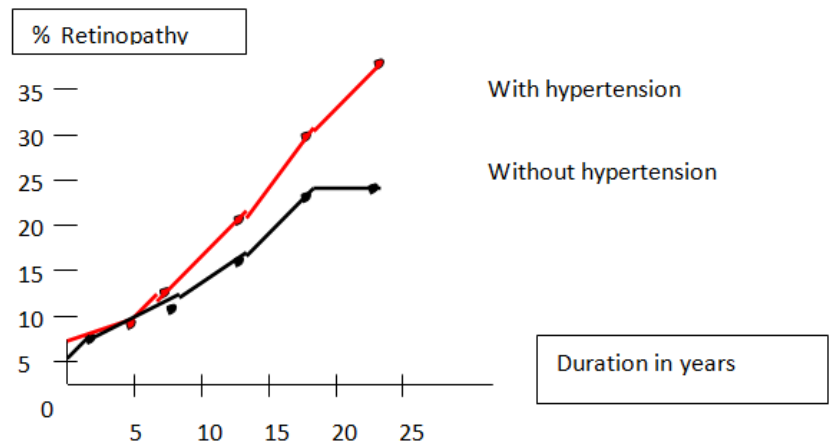

Fig. 01. Diagramatic representation of $D R$ and hypertension

It is clearly shown in figure 01 that there is an increased risk of getting diabetic retinopathy among the diabetics with the presence of hypertension than among non hypertensive patients with diabetes.

\section{Discussion}

A total of 2603 diabetics were examined.Majority were Sinhala males in Galle district with a diabetic duration of 6 $15 \mathrm{yrs}$. The total prevalence of DR was $7.53 \%$. Bilateral retinopathy was identified in $5.5 \%$ and unilateral retinopathy in $2.0 \%$. In the age specific DR showed that the lowest value of $1.31 \%$ in the in the age group of below 30 yrsand the highest value of $10.9 \%$ was observed in the age category of $51-60 \mathrm{yrs}$. The total prevalence of maculopathy was observed in $0.57 \%(0.6 \%)$ with a higher age specify value in $51-60$ yrs age group (0.8). The prevalence of Pre- proliferative and proliferative retinopathy was only $0.12 \%$ in the study population. A steady increase was shown in the appearance of DR with the duration of diabetes mellitus amounting to $30.0 \%$ in diabetics of over 20 years.

The association of diabetic retinopathy and the presence of hypertension was sorted in all diabetic retinopathy cases. It showed that there is a steady increase of prevalence among the cases with hypertension. Table 10 shows the diabetic duration and the presence of hypertension. It clearly indicate that in different duration categories the occurrence is more among hypertensives. Whether the control of hypertension reduce the risk of incidenceand progression of DR is not answered in this study. It needs a properly designed clinical trial.

The results of this analysisindicate that diabetic retinopathy affects approximately 10percent of the diabetic population who are 50 years and older. An estimated 18 percent of such diabetics without hypertension are at risk of developing vision threatening diabetic retinopathy while those with hypertension have double the risk of developing the same. It is shown in this study that the general population prevalence rates of DR are likely to be lower in younger persons. This may be due to the fact that the lower prevalence of DM in the younger age groups and the duration as well. At the same time a decline of prevalence is shown above the age of 61 years. A similar pattern of declining has shown in WESDR study. [10]This may be due to reduced survival among elderly people with DR. Whether DR is a life threatening marker has tobe sorted in future research.Further research using nationally representative sample would be useful to sort the risk of developing DR in different ethnic groups in Sri Lanka. 


\section{Conclusion}

The prevalence of diabetic retinopathy in the world is increasing substantially [2]. In Sri Lanka the prevalence of $\mathrm{DM}$ is also rising. Nearly 8persons out of 100 diabetics have vision threatening DR. When it is associated with Hypertension which is also common with the age, the occurrence is higher. This is a substantial public health problem. Therefore the policies should be directed towards improving primary and secondary preventive programmes.

\section{References}

[1] Klein $\mathrm{R}$ The Epidemiology of Diabetic Retinopathy,In:WilliumG,PickupJ,eds.Text Book Of Diabetes,London, Blackwells1991:2:537-563

[2] John $\mathrm{H}$ Kepmen et alThe prevalence of diabetic retinopathyamong adults in the united states, Arch Ophthalmol2004:122(4)552-563

[3] Retinopathy working party. A protocol for screening for diabetic retinopathy in Europe. Diabetic med 1991;8 Symposium:S4-S10
[4] British multi center study group. Photocoagulation for proliferative diabetic retinopathy: a randomized controlled clinical trial using the xenon-arc.Diabetologia 1984;26:109-15

[5] .American academy of Ophthalmology, Preferred practice pattern;Diabetic retinopathy, San Francisco, calif,American ACADEMY Ophthalmology 1998

[6] Evans JE, Rooney C, Ashwood F, Dattani N, Wormald R, Blindness and partial sight in England and walse: April 1990March 1991. health trends 1996;28 (1): 5-12

[7] The early treatment diabetic retinopathy study research group. Photocoagulation for diabetic macula oedeme. Early treatment diabetic retinopathy study report No 1. Arch ophthalmol 1985; 103:1796-806

[8] Early treatment diabetic retinopathy study research group ;Grading diabetic retinopathyfrom stereoscopiccolour fundus photographs, Ophrthalmology.1991;98(supple)786-806

[9] Wilson JMJ, JungnerG.Principals and practice of screening for disease. WHO public health paper1968:34

[10] Klein et al WESDR study; Four year incidence and progression of diabetic retinopathy when age at diagnosis is 30 years or more ,Arch Ophthalmol1989,107244-249 